
\title{
28 Research Soure \\ Twin Vaginal Deliveries: Impact of Delivery Time Interval on Twin B
}

\section{Elliot M Levine ( $\nabla$ infodoctor@gmail.com )}

Advocate Illinois Masonic Medical Center https://orcid.org/0000-0002-0097-6252

Norman A Ginsberg

Advocate Illinois Masonic Medical Center, Northwestern University Medical Center

https://orcid.org/0000-0002-9252-3030

\section{Leah Delfinado}

Advocate Illinois Masonic Medical Center

\section{Mora Ghobrial}

Advocate Illinois Masonic Medical Center

\section{Research Article}

Keywords: Twin pregnancy, Vaginal delivery, Birth weight, Perinatal, Twin delivery interval, Cesarean

Posted Date: May 7th, 2021

DOl: https://doi.org/10.21203/rs.3.rs-386147/v1

License: (1) (1) This work is licensed under a Creative Commons Attribution 4.0 International License. Read Full License 


\section{Abstract}

\section{Background:}

A vaginal twin delivery is a natural commonplace occurrence, but which can sometimes present a concern which may require action. Recently, the delivery time interval has been recognized as a variable that can be helpful for its safe conduct.

\section{Objectives:}

To view the delivery time interval in an obstetric population undergoing a twin vaginal trial of labor in consecutive deliveries during a specified time period.

\section{Study Design:}

A retrospective observational cohort of twin vaginal trials of labor was investigated to view the delivery time interval and its association with other factors, such as birth weights and the need for cesarean delivery of the second twin. The twin deliveries were divided into 2 groups, those with a delivery time interval of $\leq 30$ minutes (Group A) and those with a delivery time interval of $>30$ minutes (Group B), in a single institution.

\section{Results:}

No perinatal outcome difference was found between Group A (248 patients) or Group B (72 patients). However, 13 patients in Group B required a cesarean birth for a safe delivery, and 3 patients in Group A. The birth weight difference between each Baby A and Baby B varied according to the delivery time interval.

\section{Conclusion:}

The delivery time interval for vaginal twin deliveries may be useful to predict the need for a cesarean delivery of the second twin. The birth weight difference between Baby A and Baby B may be responsible for this finding.

\section{Introduction}

The status of the second twin may be of concern during a vaginal delivery, and the twin delivery time interval (DTI) may be pertinent to this. There may be a relatively worse perinatal outcome of the second twin at vaginal delivery, possibly correlating to the DTI of those vaginally delivered liveborn twins. ${ }^{1-5}$ Though at cesarean delivery, this interval is negligible, yet for a vaginal delivery, there can be a considerable delay of delivery of Baby B (the second twin). When speaking of a delayed delivery of the second twin, however, the delay spoken of in this report, is on the order of minutes or hours, not days as can sometimes occur preterm. ${ }^{6}$ Although there can be multiple ways of measuring perinatal outcome, 
since the assessment of cord $\mathrm{pH}$ has not been uniformly performed at our institution over the years, the most consistent and clinically meaningful measure for the purpose of this investigation is the 5-minute Apgar score as the perinatal outcome measurement tool. The institution's data set of vaginal deliveries over the past couple of decades offers an ability to review its experience, possibly identifying guidelines as to the optimal inter-twin delay that should be best tolerated. This has been explored within the medical literature, but with no definitive conclusion. ${ }^{3}$ So, the authors sought to explore the dataset of this institution, contained in its Structured Query Language (SQL) perinatal database (PG Works) to possibly identify an answer to this question.

\section{Methods}

A SQL perinatal database was used to extract and analyze the perinatal data regarding all term and near term ( $\geq 34$ weeks of gestation) liveborn vaginal twin deliveries, from January 1, 1992 through December 31, 2019. The parity, birthweight, delivery time, Apgar scores, delivery types, Neonatal Care Unit Admissions (NICU) admissions, and need for a cesarean delivery for the second twin were reviewed. The chorionicity of the twin gestations were not consistently noted in the medical record and therefore not reflected in this report. Group A includes the twins for whom the DTI was $\leq 30$ minutes, and Group B includes the twins for whom the DTI was $>30$ minutes. Analysis of the 5-Minute Apgar scores of these groups were calculated. A t-test statistical analysis was performed on the parametric data (e.g., birthweight), and a Chi square and Fisher Exact analysis was performed for the dichotomous data. Approval from the Advocate IRB was obtained for this retrospective investigation.

\section{Results}

In our institution, 320 term and near term ( $\geq 34$ weeks of gestation) vaginal liveborn twin births occurred from January 1, 1992 through December 31, 2019. In this same population, 248 babies delivered $\leq 30$ minutes (DTI) as the second twin, while 72 delivered with a DTI > 30 minutes. Most deliveries appear to have been performed in the operating room as a double setup. Sixteen twins delivered by Cesarean, as the discordant 2 nd twin delivery. It should be noted that each of the A twins had a cephalic presentation, and it was ultimately determined that the $B$ twins had a cephalic or breech or transverse presentation after delivery of twin A. Most of those breech presenting births were delivered by vaginal-assisted breech. The number of cases for which external cephalic version (ECV) was attempted (or successful) on twin $B$ was not documented in this report. Notation in the medical record was not consistently made as to the presentation of twin B. In Group A, the number of babies with a 5-minute Apgar of the 2nd twin that was $<7$ was 4 , whereas in Group B, the number of babies with a 5 -minute Apgar of the 2 nd twin that was $<7$ was 2. A Fisher exact statistical comparison yielded a $p=0.31$. There was no significant difference of the number of NICU admissions between the two groups. Thus, neonatal harm was not found regarding the DTI. The number of nulliparous moms in this population was 119 (37\%), and there was no significant difference in the nulliparous parturients between the A and B groups. These data can be seen in Table 1 . 
Table 1

Twin Data for Group A and Group B

\begin{tabular}{|llll|}
\hline & Group A & Group B & $p$ \\
\hline Number of cases & 248 & 72 & \\
\hline DTI mean & 21 minutes & 78 minutes & \\
\hline DTI range & $1-30$ minutes & $31-468$ minutes & \\
\hline $\begin{array}{l}\text { Discordant delivery } \\
\text { (Cesarean for twin B) }\end{array}$ & $3(1.2 \%)$ & $13(18 \%)$ & $<0.001$ \\
\hline Birthweight of 2nd twin, mean & 2519 grams & 2631 grams & 0.13 \\
\hline 5-minute Apgar of 2nd twin $<7$ & $4(1.6 \%)$ & $2(2.8 \%)$ & 0.31 \\
\hline NICU admissions of 2nd twin & $90(36.3 \%)$ & $28(39 \%)$ & 0.8 \\
\hline DTI = Delivery Time Interval & & & \\
\hline NICU = Neonatal Intensive Care Unit & & \\
\hline
\end{tabular}

Considering the Group B second twins (those with a DTI of $>30$ minutes), the average birthweight was 2631 grams, whereas for Group A, the average birthweight of the second twin was 2519 grams. This 137gram average birthweight twin discrepancy was $5 \%$ of the A Group average birthweight. The birthweight difference between baby $A$ and baby $B$ for each twin delivery in this cohort was computed, and then sorted into the two groups (see Fig. 1). If the birthweight of twin A was greater than twin B, B minus A had a negative value, and if twin $A$ was smaller than twin $B$, that value was positive. The birthweight difference for Group A was -53 grams, while for Group B, it was +77 grams $(p=0.06)$. Of the 72 Group B second twins, $13(18 \%)$ required a cesarean delivery for the second twin birth, as compared to $3(1.2 \%)$ of Group A. The need for cesarean delivery for the second twin birth may be related to this birthweight difference. The indications for the cesareans performed are listed in Table 2. 
Table 2

Indications for Cesareans performed.

\begin{tabular}{|ll|}
\hline Date & Indications \\
\hline $7 / 16 / 1996$ & 36 weeks, unknown presentation of twin B \\
\hline $5 / 5 / 1998$ & Fetal compromise \\
\hline $6 / 13 / 1998$ & 37 weeks, unknown presentation of twin B \\
\hline $6 / 20 / 2003$ & 36 weeks, unknown presentation of twin B \\
\hline $6 / 29 / 2005$ & Cord prolapse of Twin B \\
\hline $9 / 9 / 2008$ & 37 weeks, unknown presentation of twin B \\
\hline $10 / 9 / 2008$ & Twin B transverse lie \\
\hline $4 / 24 / 2009$ & Twin B Fetal compromise \\
\hline $5 / 14 / 2009$ & Twin B transverse lie \\
\hline $10 / 13 / 2009$ & Funic presentation, Breech \& fetal compromise \\
\hline $9 / 12 / 2011$ & Twin B frank breech \\
\hline $6 / 19 / 2012$ & Twin B cord prolapse \\
\hline $6 / 27 / 2012$ & Twin B single footling breech \\
\hline $5 / 1 / 2015$ & Twin B fetal bradycardia \\
\hline $2 / 26 / 2017$ & Failed External Cephalic Version, transverse presentation \\
\hline $10 / 30 / 2019$ & Frank breech, cord prolapse \\
\hline
\end{tabular}

\section{Discussion}

Though in some medical literature, it has been shown there is somewhat lessor perinatal outcome of the 2nd vaginally delivered twin with a DTI of greater than 30 minutes, yet in this case series there was no such conclusion. However, the number of discordant deliveries (i.e., vaginal-cesarean) may be worthy of note, in that $18 \%$ of those having a DTI $>30$ minutes required a cesarean mode of delivery to provide a safe birth of the second twin, rather than $5 \%$ of the total cohort.

When vaginal delivery is not medically contraindicated, a term twin vaginal delivery should be considered, as evidence shows that no route of delivery has any advantage over the other in most circumstances. ${ }^{7}$ In spite of this, a trend towards an increasing rate of scheduled cesarean deliveries for twin gestations has been seen. ${ }^{8}$ As the twin delivery time interval between vaginal twin births can vary, one can consider a delay of greater than 30 minutes for the second birth, as potentially concerning. Though attendance to perinatal well-being is always needed during the supervision of a course of any labor, there is the 
additional concern of a potentially discordant birth. Approximately $4-5 \%$ of twin vaginal trials of labor (VTOL) require a cesarean for the second twin birth. ${ }^{9,10}$ According to this current case series, a DTI of > 30 minutes may indicate the need for cesarean delivery in $18 \%$ of those cases, as opposed to its $5 \%$ risk within the entire data set of 320 cases. These findings may have implications for those hospitals requiring sufficient lead time for assembling an operative team which may be necessary to perform a cesarean delivery.

The weakness of this work lies in the limited size of the studied population. As can be seen in the reported results, statistical significance was not evidenced for the perinatal outcome, and the difference between the groups only approached significance $(p=.06)$. If the same comparison of birthweight differences of twins, with regard to DTI, is conducted in a larger population, statistical significance could possibly be found. The strength of this investigation, however, rests with the ability to identify the variables important in this common and appropriate procedure of vaginal twin deliveries.

Though the estimated fetal birthweight (EFW) of the second twin, compared to that of the first twin, may contribute to the DTI, sufficient antepartum sonographic resolution may be inadequate to make a prediction for the vaginal twin birth. Therefore, alertness and consideration of the DTI is necessary while performing a twin vaginal delivery.

\section{Declarations}

No funding provided

Conflicts of interest - none

Data is from the hospital's electronic medical record system, and its proprietary

Structured Query Language (SQL) perinatal information system

Ethics approvals obtained

Advocate IRB 1605593-1 (Exempt)

Consent for participation or publication: not applicable

\section{Authors' contributions:}

Elliot M. Levine, MD

Project development, data collection and analysis, reference checking, manuscript writing and editing

Norman A. Ginsberg, MD

Project development, reference checking, manuscript writing and editing 
Leah Delfinado, MD

Manuscript writing and editing

Mora Ghobrial, MD

Manuscript writing and editing

\section{Acknowledgements:}

Lourdes Pena Data Entry Specialist, Department of Obstetrics and Gynecology

Advocate Illinois Masonic Medical Center, Chicago, Illinois, USA

For Data entry and analysis of twins in departmental SQL system

\section{References}

1. Axelsdottir I, Ajne G (2019) Short-term outcome of the second twin during vaginal delivery is dependent on delivery time interval but not chorionicity. J Obstet Gynaecol 39(3):308-312

2. Algeri P, Calligari C, Mastrolia SA, Brienza L, Vaglio Dessitore I et al (2019) What is the effect of intertwin delivery interval on the outcome of the second twin delivered vaginally? J Matern Fetal Neonatal Med 32(20):3480-3486

3. Lindroos L, Elfvin A, Ladfors L, Wennerholm UB (2018) The effect of twin-to-twin delivery time intervals on neonatal outcome for second twins. BMC Pregnancy Childbirth 18(1):36

4. Benito M, De Bonrostro C, Agustin A, Roca M, Campilos JM, Castan S (2019) Impact of intertwin interval on short-term neonatal outcomes of the second twin in dichorionic pregnancies with vaginal delivery. Int J Gynaecol Obstet 145(2):193-198

5. Swanson K, Grobman WA, Miller ES (2017) The association between the intertwin interval and adverse neonatal outcomes. Am J Perinatol 34(1):70-73

6. Louchet M, Dussaux C, Luton D, Goffinet F, Bounan S, Mandelbrot L (2020) Delayed-interval delivery of twins in 13 pregnancies. J Gynaecol Obstet Hum Reprod 49(2):101660

7. Hofmeyr GJ, Barrett JF, Crowther CA (2015) Planned caesarean section for women with a twin pregnancy. Cochrane Database Syst Rev 12:CD006553

8. Tal A, Zafran N, Peretz H, Garmi G, Romano S, Salim R (2019) Trend in cesarean delivery rate among twin pregnancies over a 20 years epoch and the accompanied maternal and perinatal outcomes. Eur J Obstet Gynecol Reprod Biol X 3:100023

9. Schachter-Safrai N, Karavani G, Haj-Yahya R, Ofek Shlomai N, Porat S (2018) Risk factors for cesarean delivery and adverse neonatal outcome in twin pregnancies attempting vaginal delivery. Acta Obstet Gynecol Scand 97:845-851 
10. Mei JY, Munoz HE, Kim JS, Szlachta-McGinn A, Blat C, Rao R, Han CS, Irani RA, Afshar Y: Rates of cesarean conversion and associated predictors and outcomes in planned vaginal twin deliveries. Am J Perinatol 2020

\section{Figures}

\section{Twin Birthweight Difference (B-A)}

\section{Associated with Delivery Time Interval $\leq 30$ minutes and DTI $>30$ minutes}

[320 Twin Pair Vaginal Deliveries]

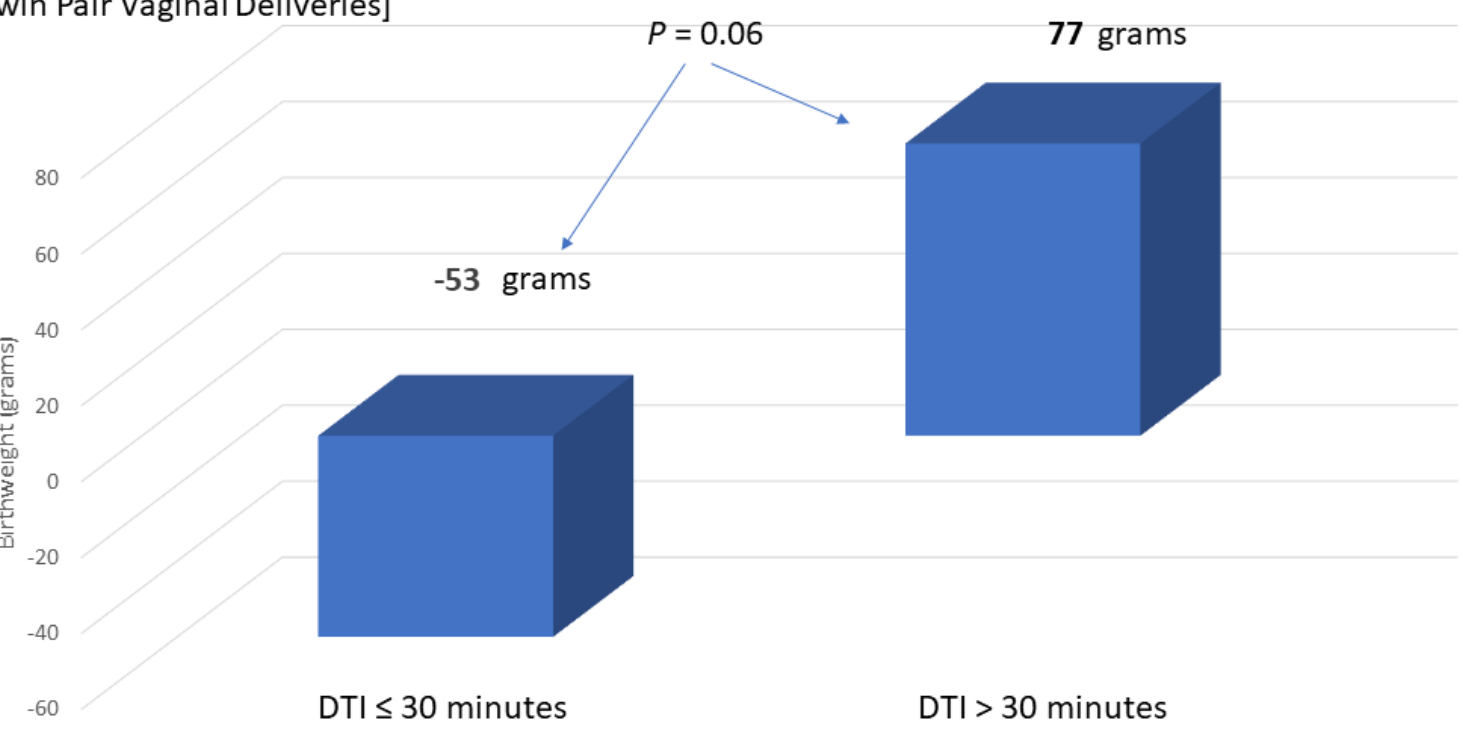

Figure 1

Twin birthrate difference 